\title{
Streptococcus anginosus
}

National Cancer Institute

\section{Source}

National Cancer Institute. Streptococcus anginosus. NCI Thesaurus. Code C86782.

A species of facultatively anaerobic, Gram positive, cocci shaped bacteria in the phylum Firmicutes. This species is positive for arginine deamination, esculin hydrolysis and beta glucosidase and negative for urease, catalase, sialidase and hyaluronidase. It can ferment amyg dalin, lactose, salicin, cellobiose, trehalose and raffinose but not arabinose, glycerol, inulin, sorbitol, mannitol or ribose. S. anginosis is found in normal human urogenital and gastrointestinal tracts and is involved in opportunistic infections of abscesses. 